$\frac{331}{7 \sqrt{n}}$<smiles>[Se]=[Se]12CC([Se]1)[Se]2</smiles>

\title{
A Portable Computer to Reduce Gamma-Ray Spectra for Plutonium Isotopic Ratios
}

\section{Wayne D. Ruhter \\ David C. Camp}

ISPO Task A.63

Development Report

\section{May 15, 1981}
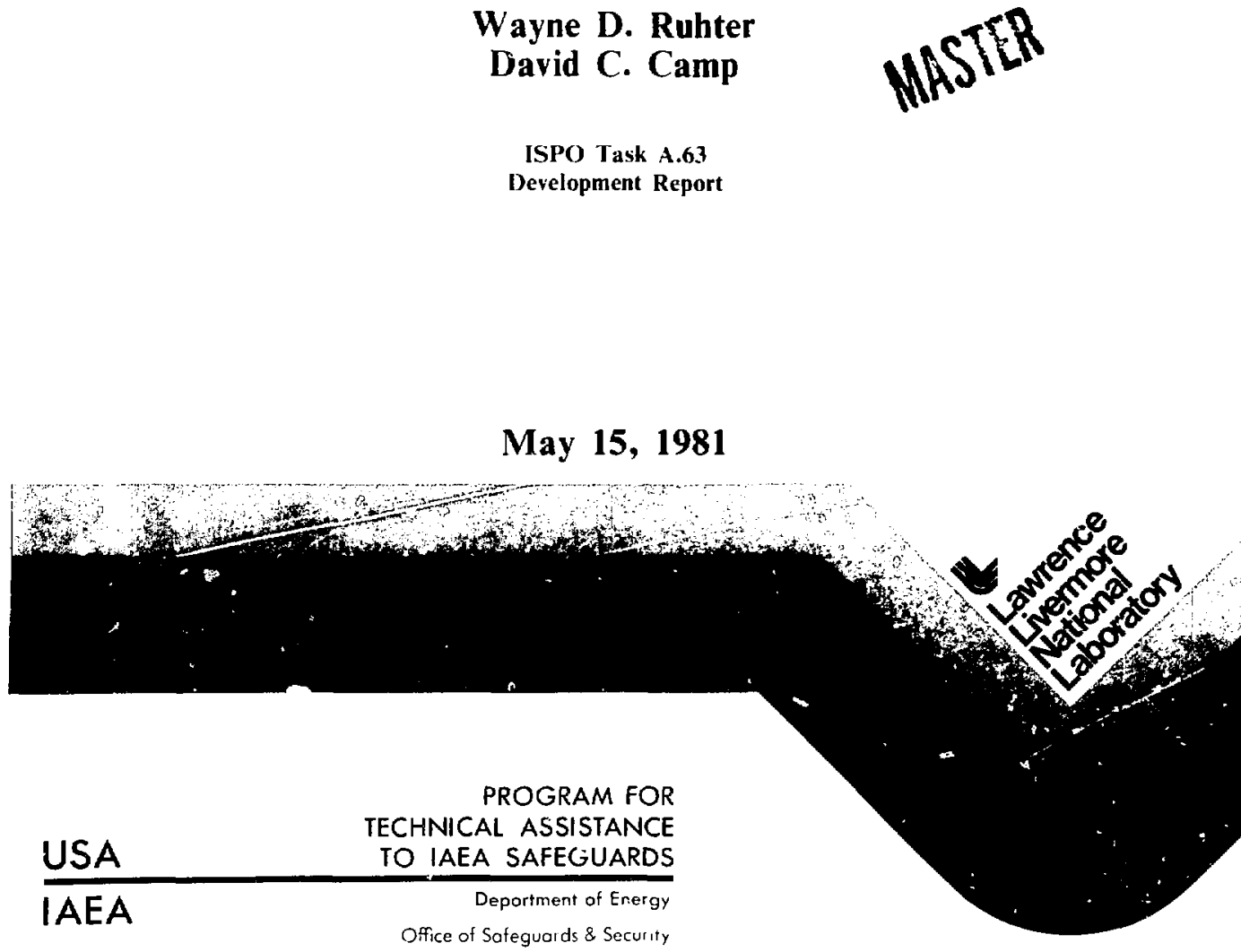


\title{
A Portable Computer to Reduce Gamma-Ray Spectra for Plutonium Isotopic Ratios
}

\author{
Wayne D. Ruhter \\ David C. Camp \\ ISPO Task A.6.3 \\ Development Report
}

Manuscript date: May 15,1981

LAWRENCE LIVERMORE LABORATORY

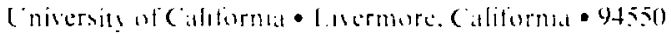




\section{CONTENTS}

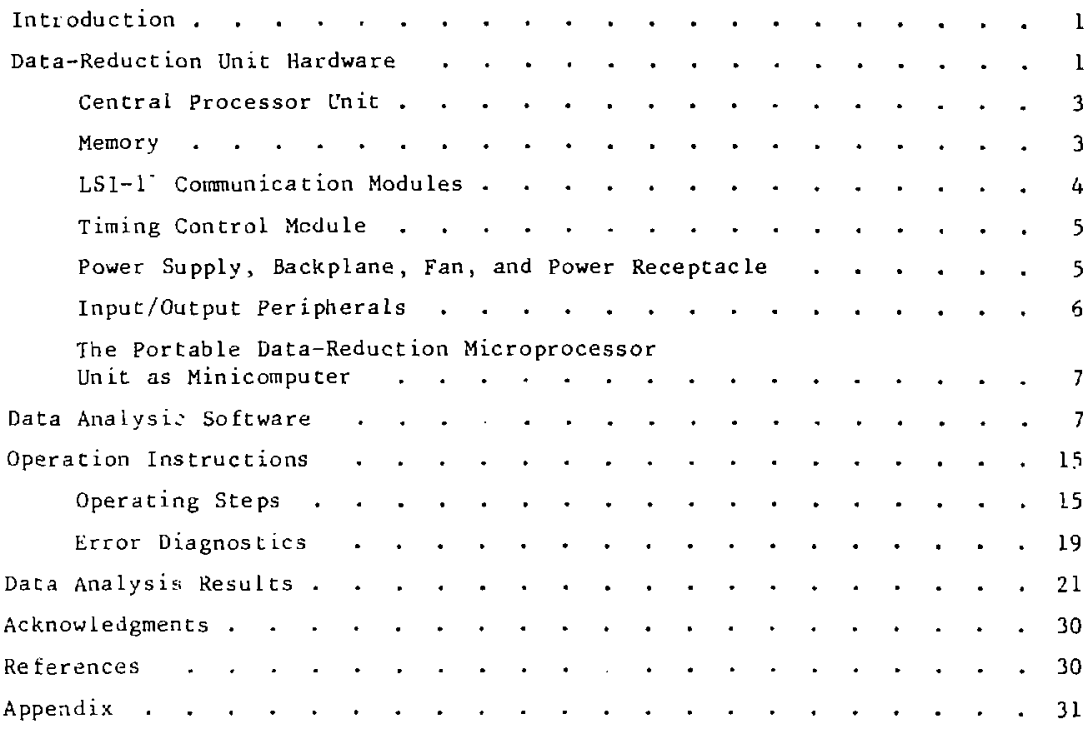




\section{A PORTABLE COMPUTER TO REDUCE GAMMA-RAY SPECTRA}

FOR PLUTONIUM ISOTOPIC RATIOS

\section{INTRODUCTION}

In response to Task A.63 of the International Safeguards Project office (ISPO), to upgrade measurement technology used by the International Atomic Energy Agency (LAEA), we have designed and programmed a portable data-reduction microprocessor. The unit allows in-fieid reduction of gamma-ray spectra and interfaces with the IAEA's multichannel analyzers--the 1000- or 2000-channel memory Silena BS27/N.

In this report, we describe the components used in assembling the microprocessor unit, i.e., the hardware; the software used to control the unit; and the mathematical furmulation used to obtain isotopic ratios from the gamma-ray data. We also present a simple overview of the ulit's operation and the results of tests on gamma-ray spectra that sought to verify the unit's operating characteristics and to determine the precision and effectiveness of the software developed for data reduction.

\section{DATA-REDUCTION UNIT HARIJWARE}

The portable data-reduction microprocessor unit (Fig. 1 ) is contained in a 30.5- x 30.5- x 22.9-cm extruded aluminum case, weighs $10 \mathrm{~kg}$ (22 $\mathrm{lb})$, and operates on either $110 \mathrm{VAC}(60 \mathrm{~Hz})$ or $220 \mathrm{VAC}(50 \mathrm{~Hz})$. It uses an LSI-1l/2 microprocessor (Digital Equipment Corporation) and two memoriesu-a irogrammable read-oniy menory (PROM) for storing operating snfisare and a random access memory (RAM) for scoring data during reduction--to give a powerful yet easy to use data-reduction system. The operator interacts with the unit through a decimal keyboard and a 20-character alphanumeric display. A 7-key function and a l0-digit icyboard (see Fi?. l) provide renote control of the Silena multichannel analyaer ( $Y C A$ ) and the votry of data into the unit. Communication between the unit and the Silena MCA is accomplished by a parallel interface module that cransfers data at a rate of 10,000 bytes/s. Thus, a 1000-channel spectrum is transferced in less than $1 \mathrm{~s}$. The hard copy data-reduction results are produced by a 20-character thermal printer. 


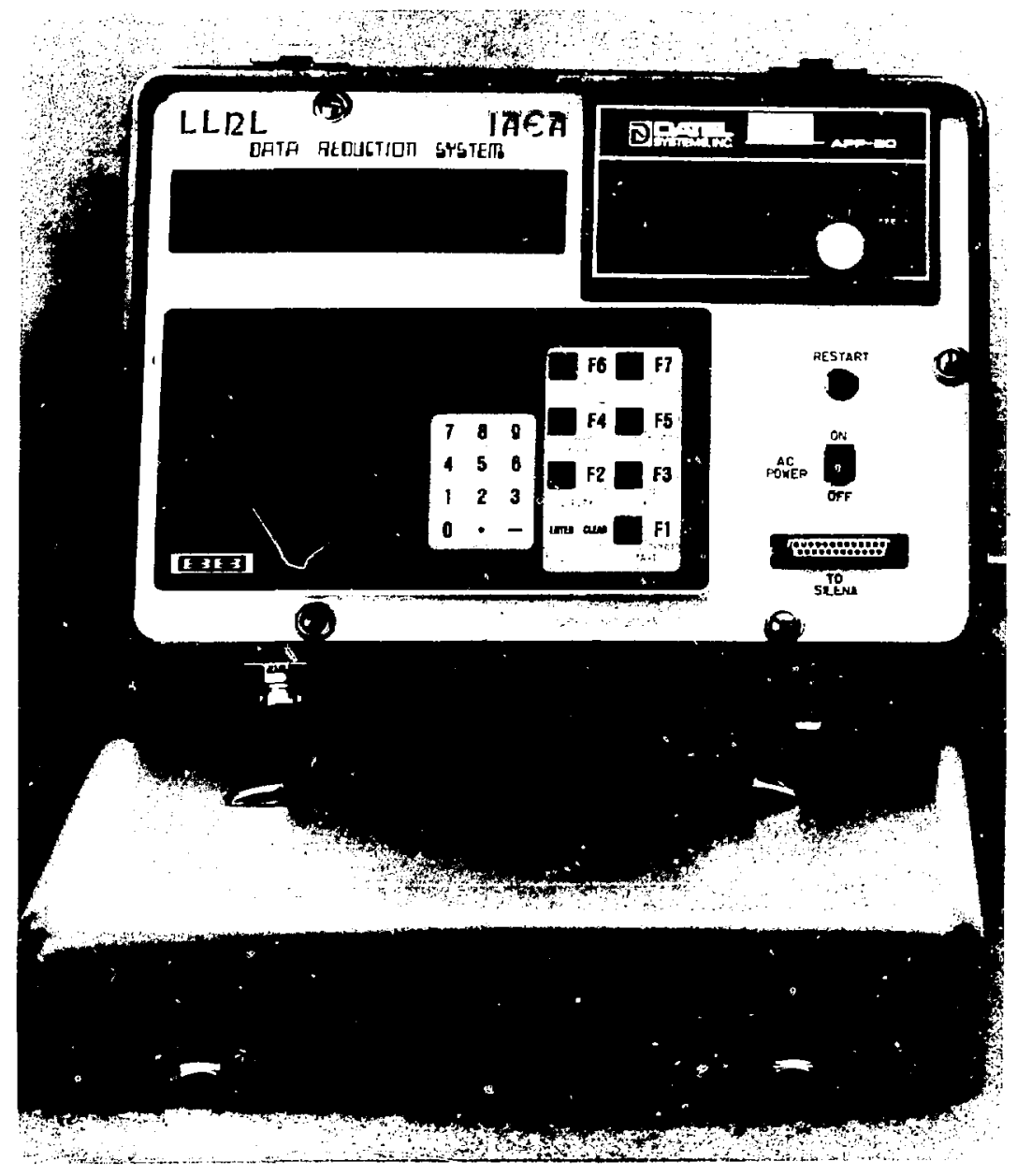

FIG. 1. The portable datareduction unit. 
CENTRAL PROCESSOR UNIT

The LSI-11/2, the central processor unit (CPU) of the portable datareduction microprocessor unit, is capable of addressing $32 \mathrm{~K}(\mathrm{~K}=1024) 16-\mathrm{bit}$ words of memory. A lo-bit ouffered parallel input/ontput LSI-la bus with asynchronous operation allows the processor and its system components (memory and input/output peripherals) to run at the highest speed possible. An Extended and Floating-point Instruction Sets (EIS/FIS) chip provides fixel-point multiplication, division, and multiale sititin? io louble-precision arithmetic, as wall as floating-point adition, subtraction, multiplication, ard division. Thus, the tol-11/2 is a lb-bit nicroconputer with the speed and instruction set of a minicompucet. The processor board a dual-height moiule) nasures $14.0 \times 21 . b \mathrm{em}$. The poutr requiremencs are $+5 \mathrm{~V}$ it 1.0 a and +12 V at 0.22 i.

VIE:SOKY

The mit ins a prostammble read-only memory (PRoil) for storing operating suftware and a randun accoss nemory (RAS) for storing datu during reduction. The pRuY is not volatile--it reiains ils contents when operaling power is renoved; thus, prograns and data are still available when operating power is restored. The kiy, however, is volatile-when operating pows is removed, its contients ari lost.

A pkod is identified by the cype ar integrated circuit (IC) chip it uses;

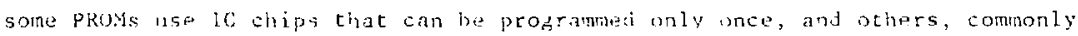
referred Lo as erasanle and programable raadonlv menories (apkod), use ic chips that can be wased by bigh-intensily ultravioled ligh and then reprogrammed. The dita-reduction system PROM uses an iNTE: 27li-type erasable

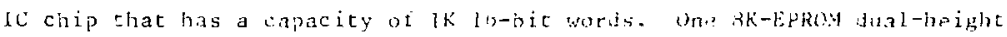
modide holds eight of these chips; so two are necessary to provide lok of prugl menory. The power requiremencs for each module are $+5 v$ at 1 is i and $+12 V$ at $0 . \cup 2 \mathrm{~A}$.

\footnotetext{
*A clear quartz wi low placed over the pRus Il chip allows the altraviolet light to be directe men the semiconduclor material, thus erasing the program.
} 
The dual-height RAM is a dynamic, high-speed, read/write memory. The programs in che PROA use this memory area to store variables during data reduction. For instance, spectral data from the MCA are stored in the RAY The RA: module has $32 K$ words of memory, $12 \mathrm{~K}$ of which are accesses by the CPU. It has its own memory-select switches to configure the memory bank. The power requirements of this module are $+5 \mathrm{~V}$ at $1.0 \mathrm{~A}$ and $+12 \mathrm{~V}$ at $0.3 \mathrm{~A}$.

\section{LSI-11 CIMAUNLCATLON RODULES}

line data reduction system requires both a serial interface indule and a parallal interiace module. The keyboard, the alphanumeric display, and che printer comnunicate with the LSI-l l through serial interface channels, and tile Silena MCA and the LSI-1l commicate chrough a parallel interface channel.

lo meet the serial communication requirements, we used the dual-height [LVl1-. asynchronous serial-line/interface norite. This module controls four independent serial input/output cinannels to the LSI-11 tus, three ot dhich are used by the data-reduction system. Tha interface transuits and recuives lata from a peripheral tevice over lilectronics Industry Associacion (E[A) data-leads-only lines, making the interface RS-2320, RS-422, and RS-423 compatible. Baud rates Erom 150 to $38.4 k$ can be selected for each channel. ille power requirements of the board are $+5 V$ t 1.0 A and $+12 V$ at 0.2 , A.

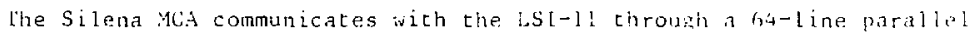
input/output modile with TTL logic. Ihis modile is capable of connecting rt external parallel inpuc/oucput lines to the ist-11 bus. All input/oucput lines can be configured as either input or nutput lines, in incerments of eight, by using plug-in components. The powe: requirements of tinis module are $+5 \vee$ at $1.25 \mathrm{~A}$.

This module is ideally suited for communication. wich the silena vich because of its parallel inerface--the vod. 7500-11. This unit, specifically designed for connection $t s$ a computer capable of accepting data in a parallel riode, is a circuit card that plugs into tin last of the three input/output connectors in the analyzer. The intertacs logic sigrals are locatel at a 25-pin connector on the analyzer's raar panel. The? Mod, 7500-11 is unidirectional, only transferring data from the Mcit to the computer, and hac a data transfer rate of 10,000 characters/s. It sends data from channels 0-1017 of the Silena memory to the computer over eight lines, character by character. 
Since each character consists of 8 oits in ASCil code and each channel consists of 8 characters, 8144 characters plus 41 trailing characters are sent for each spectrum. Thus, with a data transfer rate of 10,000 characters/s, the Mod. 7500-1l can transfer the entire spectrum in less than $1 \mathrm{~s}$.

Two input/output $l$ ines control the data transfer between the Silena MCA and the computer: one indicates to the computer that a character is on the data line; the other resets this datu-ready line once the character has been read. Three lines signal the analyzer status to the computer--data in, data Jut, and display mode--and six lines Lransmit operation comands to the MCA

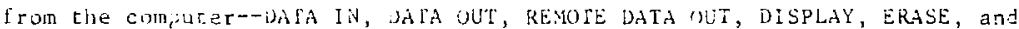
srop. These comnands will be discussel in more letail in the operations section of this report.

PILNG CONTHO, MUDUS.E

The raca-reduction unit has a timing control module that provides the time and date. This modula is a self-supporting time keeper that operates in a peripneral slot of the LsI-1l system. When the computer is off, the timing control modile will concinue to operate for up to three moncins, using power from its own rechargeable hactery. It is initialized by simple commands from tho tnicroprocassor.

POWER SUPPLY, GACKPLANE, FAS, AND PONER RECEPTACLE:

Ail of the modules and peripheral inpuc/oucput devices in tile data-reduction systen operate on direct current (Du). Hence, we nepr a device that converts irom alternating current $(A C)$ uf varving voltages and frequencies to direct curreat. A 75 -w (high-eticiancy) switching power supply fulfills this need. We chose to use a hisheficiency puwer supply instead ot a lowerficiency, or linear-type, power supply bearuse of its sina:l volume and low weight, and its ability to operate war a wider rans of input voltages and fraquencies. The motel installed in the data raduction systeln is $27.9 \mathrm{~cm}$ long by $13.1 \mathrm{~cm}$ wide by $4.3 \mathrm{~cm}$ high and weighs approxinately $\mathrm{l} .9 \mathrm{~kg}$. it ing two Je outputs: one with a rating of $5 \mathrm{~V}$ at $B d$ and one with a rating $\therefore \mathrm{E} I 2 \mathrm{~V}$ at $2 \mathrm{~A}$. The $\mathrm{AC}$ input specifications for this model are $105-130$ - and

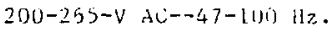


A backplane configured to accept eight 14-cm-wide (dual-height) modules distributes the power to rhe seven circuit-board modules that operate on $5 \mathrm{~V}$ and $12 \mathrm{~V}$ DC. Completely contained in the backplane is the LSI-11 bus. The bus lines are prewired to each moduie location, and each module is kept firmly in a backplane connector slot by a rugged but lightweighc card gidide assembly. The backplane with card guide is $27.4 \mathrm{~cm}$ long by $14.6 \mathrm{~cm}$ deep by $15.2 \mathrm{~cm}$ high. With the seven modules installed, this assembly weighs approximately $1.8 \mathrm{~kg}$.

A fused connecto with voltage selection connects the suitching power supply to the AC line potver. This connector eliminates the need to change internal wiring for operation at differer.t $A C$ voltages, provides a convenient fuse holder, and lets the user change comactions to the fower supply with a voltage selection card. This is a safe way of changing connections to the power supply because the power line cord must be renoved from the connector before the fuse or tile card can be accessed. The connector also has a built-in filter that protects the equipment from radio frequency interference.

To cool the internal components of the unit, we i:stalled a 11.9-cm-square by $3.8-\mathrm{cm}$-deep fan that delivers $115 \mathrm{cfm}$ of air and operates on either 120 or $220 \mathrm{~V} \mathrm{AC}$. The fan's metal housing acts as an effective heat sink for the bearing, thereby extending its life.

INPUT/OUTPUT PERIPHERALS

A 2)-character vacuum fluorescent uni: displays messages sent by the LSI-1l through the DLVll-J serial interface at 1200 baud. These messages either elicit a response from the keyboard user or indicate a condition that requires corrective ac:ion. Since the flow $\mathrm{f}$ information is in one direction only, the LSI-1l must anticipate all transmission timing. The tnit is $15.7 \mathrm{~cm}$ wide by $4.8 \mathrm{~cm}$ high by $8.9 \mathrm{~cm}$ deep, wighs approximately $300 \mathrm{~g}$, and operates on $5 \mathrm{~V} D C$ with cypical current requirements of $500 \mathrm{~mA}$. The character 1 ine is $10.2 \mathrm{~cm}$ long, and each individual character is $5 \mathrm{~mm}$ by $3.5 \mathrm{~mm}$.

A numeric keyboard terminal controls entry of data into the data-reduction program, and a seven-key function provides remote control nf the Silena MCA. The terminal, which has an eight-digit display with a seven-segment LED, receives aud transmits ASCII-coded data through one of the DLVll-J serial lines at 300 baud. The eight-digit display has an embedded 
decimal point that does not use the eight positions and a minus sigu that does. The ENTER and CLEAR keys allow verification and/or erasure of entries before they are transmitted to the LSI-11. The unit weighs only $290 \mathrm{~g}$ and operates on $12 \mathrm{~V}$ DC at a $250-\mathrm{mh}$ maximum.

Hard copy printout of the data-reduction resulss is produced by a quiet, nonimpact thermal printer. It receives its information from the LSI- 11 through one of the UVLIL-J serial lines and then prints the full $A S C I I$ character set in 20 colimns across 58.6 -mm-wide chermal paper, at a race of 1.2 lines/s, regardless of the number ct characters per Iine. On a $42-n$ ruil of paper it prints $x, f u n$ lines of tata at 2 lines/cm (approximately lon spectral analysis sutputs?. The printer $4522.2 \mathrm{~cm}$ iong by $11.2 \mathrm{~cm}$ wide by $5.85 \mathrm{high}$, weighs $2.0 \mathrm{~kg}$, and operates on $11 / 220 \mathrm{~V} A \mathrm{C}$. An internal swicch, accessible wizen the paper roll is removed, selects the voltage.

IHE PORTARLE DATA-REUCCTI AN ALCROPROCESSOK UNIT AS MLIICOMHITHS:

since the portable data-refuction woit has an available ingut rutplt channei on the DLVli-J rodule and an extra slot in the hackplane, it cosis je upgraded to a portable minicomputer if selectid interna! wiriag and swite's thanges wefe made. The ninicomituter would require a mass storage device (i.e., a floppy disk) and a Eull alphanumeric terminal. The storage device could be acconnodated by inserting an incerfaco cart into ciue remaining backplane slot, and the terminal could be connected to the spare bivil-y input output channel. Settinu tim appropriate switches on the ku nodule would provite a full $32 \mathrm{k}$ of $\mathrm{RAN}$.

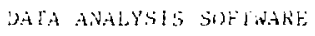

line objective at the data analysis soltware loveloped thas lar is to determine the platonim isotopic ratios from the amma-ray spectri inta. This requires determining the peaks appropriate co che isotopes of interest, a task that would be very simple it all the appropriate peats were well-isolated, single peaks. Unfortmately, the analusis must include 
complicated peak groupings because they provide the only information from which to deduce a particular isotopic abundance.

A careful analysis and interpretation of gamma-ray peaks includes the proper delineation of the peak shape, a reproducible description of the background continuum under the peak or peak grouping, and a method for unfolding peak multiplets and removing small interferences. The basic equation for describing peak shapes, developed by R. Gunnink, ${ }^{1}$ is written as follows:

$$
\ddot{y}_{i}=y_{0} \times e^{u\left(x_{i}-x_{0}\right)^{2}}+A y_{0} \times e^{B\left(x_{i}-x_{0}\right)} \times\left[1-e^{c \times a\left(x_{i}-x_{0}\right)^{2}}\right]_{\delta}
$$

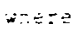

$$
\begin{aligned}
& \because=\text { net data counts } \\
& \therefore \quad=\text { peak neight } \\
& \dot{y}=\text { peak widtin parameter } \\
& \therefore_{i}=\text { crannel value of the } i^{\text {th }} \text { point } \\
& x_{. j}=\text { peak position } \\
& \therefore, \mathrm{B}, \mathrm{C}=\text { shape parameters describing the tailing function } \\
& \delta=1 \text { for } x_{i}-x_{0}<0 \\
& 0=0 \text { for } x_{i}-x_{0}>0 \text {. }
\end{aligned}
$$

Six parameters-- $y_{0}, x_{0}, a, A, B$, and C--characterize a particular gamma-ray peak (see Fig. 2). The data points $Y(i)$ in an overlapping peak multiplet are then considered linear combinations of the contributions from each peak so tinat

$$
Y(i)=\sum_{j=1}^{n} Y_{j i} \text {, }
$$

where $\mathrm{n}$ is the number of peaks. The pi.ranecers $A, A, B$, and $C$ are needed to describe the peik shape but normally are not of great interest by themselves. It simplifies the fitting process if we predecermine their values from the given spectrum and treat them as fixed rather than free parameters. 


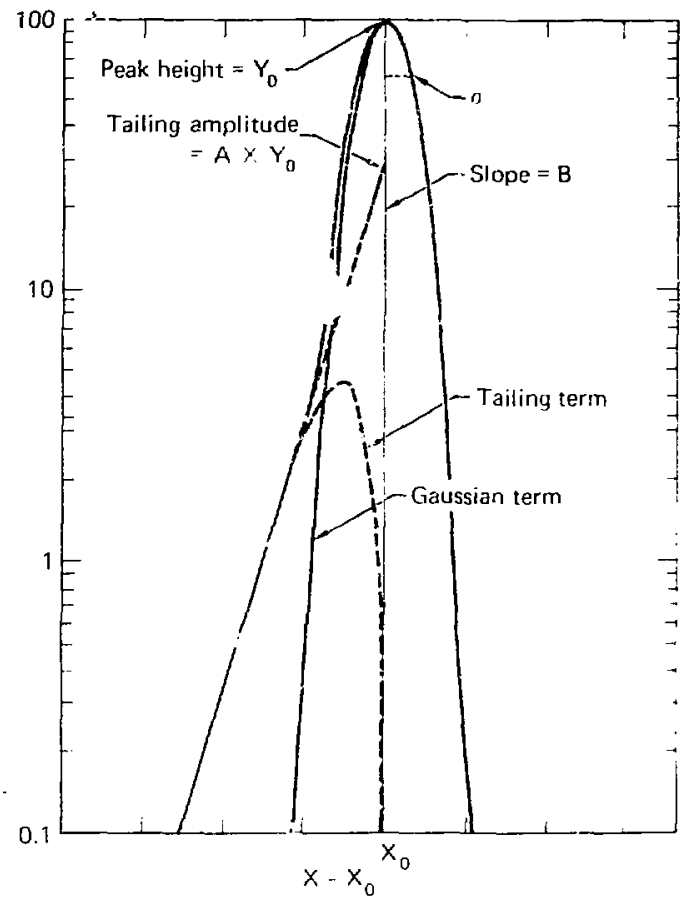

Fli. 2. A detail siowing the componencis usel to describe a peak shape.

The peak widtir parameter a ia commonly specificd by tia tull with at half maxinum (FWhy $=2.355 \mathrm{~J}$ ). This is related to 2 by

$$
u=-1 / 20^{2} \text {. }
$$

FWHM can be expressed in terins of peak porery as

$$
\left[(\text { FWHY })^{2}-0.462\right] \times\left(\text { giin }^{2}\right)^{2}=k_{l}+K_{2} \times E .
$$

The values of $k_{l}$ and $k_{2}$ can be calculated by determining the fwltr of lowand high-energy pea'.s in a spectrum. The value 0.462 is a Sheppard's 
correction for the error that results from treating all the counts in a given channel as if they were concentrated at the thannel center.

The quartities $A$ and $B$ characterize the amplitude and slope of an exponentially rising term that describes the tailing occurring on the low-energy side of the gamina-ray peak. This cerm is multiplied by $\left[1-e^{-C a\left(x-x_{0}\right)^{2}}\right]$ to reduce its contribution to zero at the peak centroid. The quantity $C$ is a racher insensitive paramiter, and a value of 0.4 appears suitable for all germanium detector systens.

Studies have shown that slope parameter B is dftector dependent oniy, whereas amplitude parameter $A$ is both detector and esergy dependent. A simple algorithi, given by $l_{n i}=C_{1}+C_{2} \times E$, describes the approximate relationship between parameter $A$ and the gama-ray energy. As in the case for $c$, we use , wo or more peaks to evaluate the constants $c_{1}$ and $C_{2}$ in this axpressioi.. Therefore, the peak shapes for a given spectrum can be predeternined from two peaks and specified in torms of six parameters: $k_{1}$ and $K_{2}$ (ased to deternine 4 ), $c_{1}$ and $c_{2}$ (used to calculate $A$ ), and $B$.

For this particular application, we use the $148.6-\mathrm{keV}$ peak of ${ }^{24} \mathrm{l}_{\mathrm{pu}}$ and the 208-keV peak of $237 \mathrm{U}$. Issually, these two peaks are the most intense peaks in the spectrum, especially for high burnup plutonium. Although the tail amplicude paramater $A$ is generally energy dependent, we must also consider poor 149.6-keV peak statistics, or poor guality spectra, or botr. Good statistical significance is required to determine $A$ accurateiy, and in most cases, the spectra encountered will not be statistically gnod. The 148.6-keV peak also has interferences on the low-ener $3 y$ side, which increases the error in establishing the energy dependerce of $\mathrm{A}$. Consequently, the core determines tine tail parameters $A$ and $B$ from the $2 . J 8-k e V$ peak and $t$ reats $A$ as constant for the spectrum.

The 148.6-keV and 208-keV peaks are alsc used as reference peaks for determining the gain and the zero-intercept of the spectrum. Using this information (assuning that the conversion gain is linear), we can compute the exact positious of the peaks to be analyzed.

If the value of $x_{0}$ in $E_{4}$. $l$ is now also known (in addition to the other shape parameters), the set of equations in Eq. 2 will no longer contain unlenowns in the exponents. This simplifies the software since the equations can be solved simply by the line: ast-squares method rather than by an iterative technique. The only free parameters remaining in tire equations are 
the peak heights. However, not all of the peak heights in a group are frez parameters since all peaks belonging to a given isotopic component are fixed by a prior calibration (i.e., the branching intensities in their decay schemes have been deterinined). Therefore, e can compute a response envelope for each isotopic component rather than for each peak and thereby reduce the number of unknowns to the number of components. This occurs before any correction for sample geometry or overal, efficiency is made.

Before we can deternine the net ara of a peak, the background beneath the peak or peak grouping must be retnoysd. This is usually cione by interpolating the background, using a straighc line or a polynomisl function. However, slich a procedure is, in pranciple, incorrect and may lead to erroneous results. Thus, we use the following pxplicit function to incerpolata background valiss beneath tive peak grouping ${ }^{1}$ :

$$
z_{i}=b_{n}+\left(i_{1 n}-b_{n}\right) \times\left(\sum_{j=n}^{j=i} Y_{j}\right) \times\left(\sum_{k=n}^{k=1 n} Y_{k}\right)^{-1},
$$

where

$$
\begin{aligned}
& B_{i}=\text { computer backupround at channel } i \\
& \mathrm{Y}_{\mathrm{i}}=\text { spectrum count of cuarne! } \mathrm{i} \\
& b_{n}=\text { auerage backersund level of the low-enerey sile ot the peak } \\
& b_{\text {in }}=\text { average hackground level of the high-energy siat of tim seak. }
\end{aligned}
$$

This fuiction produces soopthet hackerouni fteps that occur at each pak position. It works equally well fur single peaks and complax peak aroupings. rypically, the ganina-ra: spectra taken by the ldit inspectors ar" in the

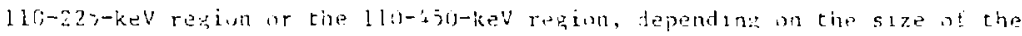

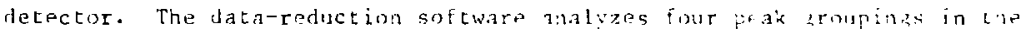

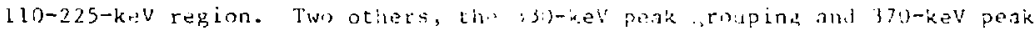
grouping, are used in the analvais it the sain is set to inclide these reaks in the spectrum. The six peak prouping ar showl in tanle 1.

The data analysis software andivas each peak grouping aporately. First, the background Aistribution is removid trom the grouping, and then $a$ response function for each isotope conkributiag to the grouping is gererated. The response functions are calculated using peak shape and branching intensit: informacion. This approach vields a set of lunear equacions whose number of 
TABLE 1. Peak groupings analyzed by the data-reduction software.

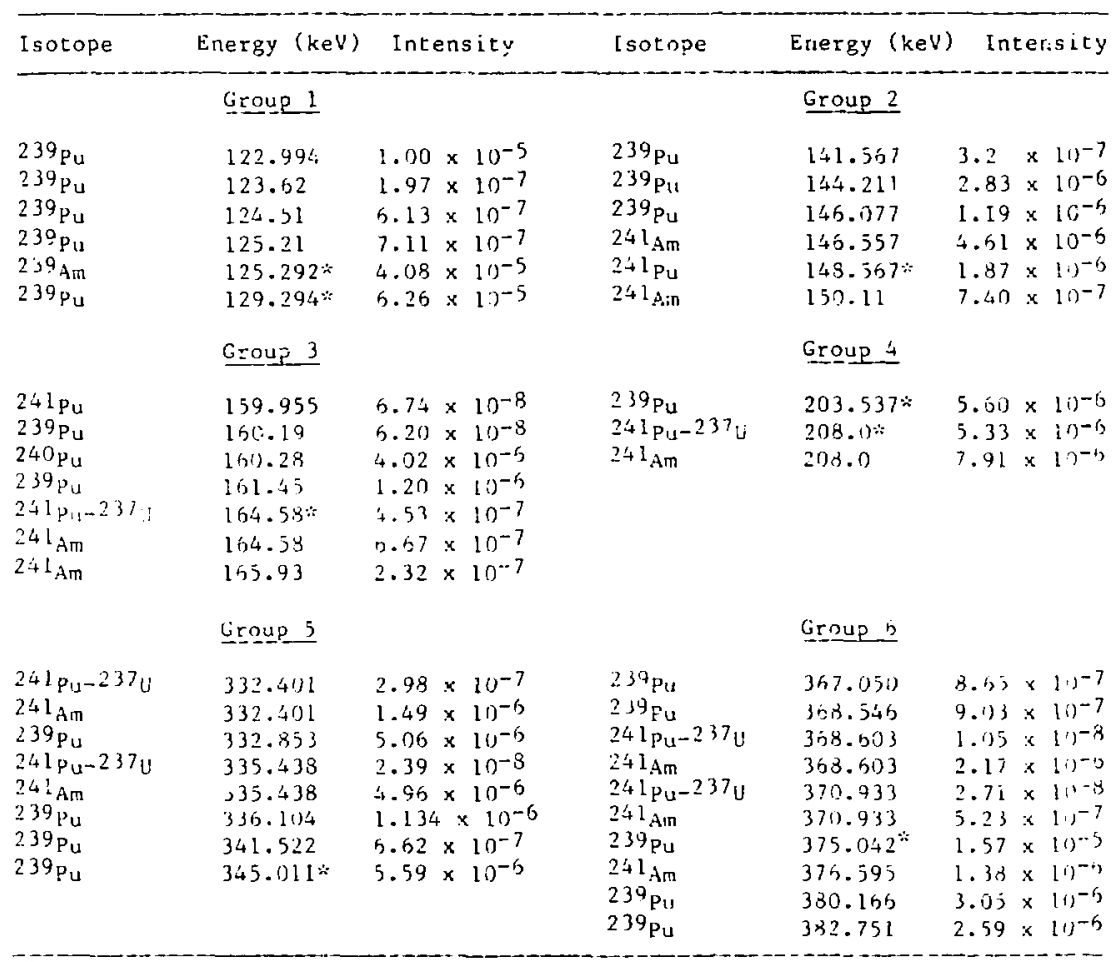

"Indicates that a peak is used for deternining the relative efficiency curve. The ${ }^{238}$ Pu $152.58-k e V$ gamma-ray peak and the 235 u $185.72-k e V$ peak are analyzed individually.

unknowns is equal to the number of isotopic components. Solving for these unknowns requires the inversion of a matrix that yields the necessary peak-height or area intormation.

The objective of the data analysis is to interpret the spectral data in terms of isotopic ratios. We cannot use a direct calibration since there is no uniformity among the samples or the IAEA's detectors. Therefore, we must consider the influence of counting efficiency and gamma-ray attenuation (due to the sample matrix or other absorbing materials) on gamma-ray peak 
tntensities. To minimize these ractors, we select sets of neighboring gamma-ray peaks from a spectrum emitted by different isotopes and ther calculate the ratio of isotopic abundances from the mama-rav intens ties of the selected sets, is ing the following, equation:

$$
A B=\frac{I_{1}{ }_{1}}{\varepsilon_{1} x_{1} \gamma_{1}} / \frac{1_{2} \mathrm{r}_{2}}{\varepsilon_{2} \bar{x}_{2} z_{2}},
$$

where

$$
\begin{aligned}
& \therefore / D=\text {, s stope ratio st liaterest }
\end{aligned}
$$

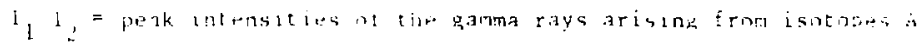

$$
\begin{aligned}
& \text { and } B
\end{aligned}
$$

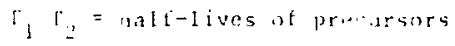

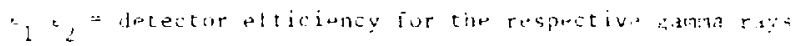

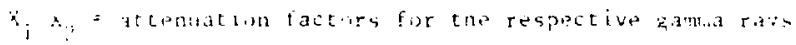

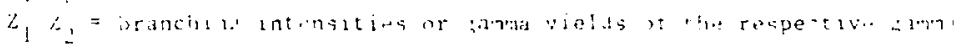

$$
\begin{aligned}
& \text { r.s.4. }
\end{aligned}
$$

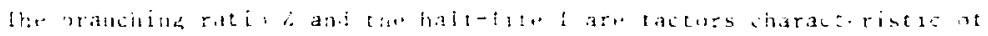

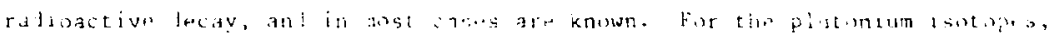

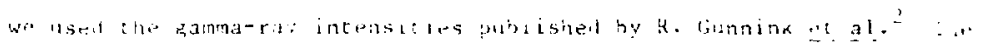

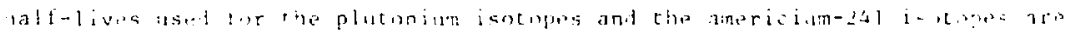

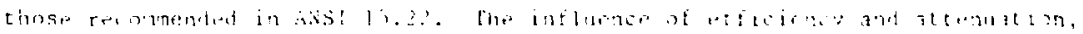

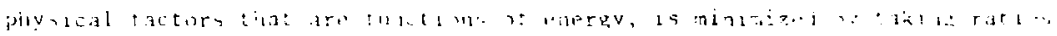

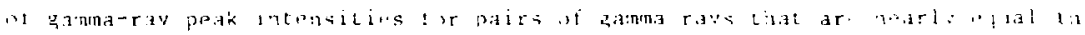

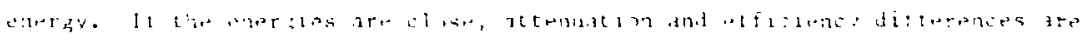

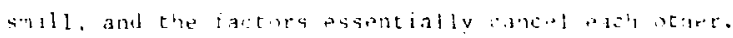

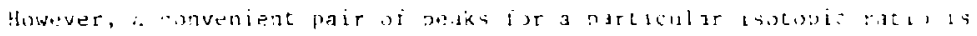

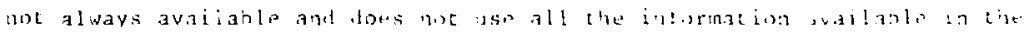

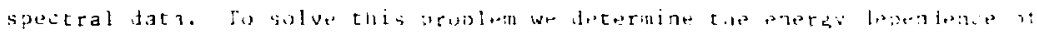

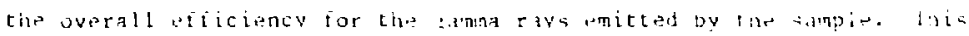

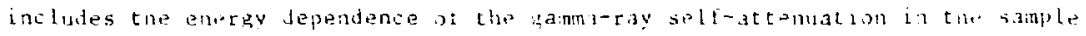

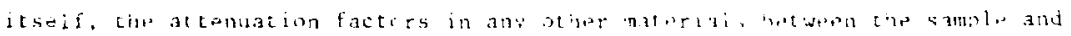
the detector efticiency, and all gemetric factors.

A seli-calibration technique is used to oblain cho necossary relative eticiency corrections from neak areas in pach spectrum neasured. treas for 
$239 \mathrm{Pu},{ }^{24 \mathrm{l}} \mathrm{Pu}$, and ${ }^{241} \mathrm{Am}$ (peaks denoted by asterisks in Table 1) are corrected for gamma-ray branching intensities and fitted to the functional form

$$
\ln \left(\frac{I_{i}}{z_{i}}\right)=a_{0}+a_{1} \delta_{1}+a_{2} \delta_{2}+\sum_{j=3}^{2} \text { or }{ }^{3}\left[a_{j+2}\left(\ln E_{i}\right)^{j}\right],
$$

using a weighted least-squares technique. The value $E_{i}$ is the energy of the peak in mega electron volts. The coefficients $a_{1}$ and $a_{2}$ normalize the ${ }^{241} \mathrm{Pu}$ and ${ }^{241} \mathrm{Am}$ data points to the ${ }^{239} \mathrm{Pu}$ data puints and obtain the $24 \mathrm{l}_{\mathrm{Pu} /}{ }^{239} \mathrm{Pu}$ and $24 \mathrm{Lm} /{ }^{241} \mathrm{P}_{11}$ isotopic ratios. IE the $330-$ and $370-\mathrm{keV}$ peak groupings are included in the speccrum, we use a cubic function to fit the data (the sum of $j$ is to 3); when only the first four peak groupings are included, we use a quadratic function. For a compiete analysis, the indicated peaks of these tour groupings must be in the spectrum.

We determine the ${ }^{238} \mathrm{Pu} /{ }^{239} \mathrm{Pu}$ isotopic ratio and the ${ }^{240} \mathrm{Pu} /{ }^{239} \mathrm{Pu}$ isotopic ratio from the ${ }^{238} \mathrm{Pu} 152.68$-keV gamma ray and the ${ }^{240} \mathrm{Pu}$ $160.28-k e V$ gamna ray after correcting their peak areas for branching intensity and relative datection efficiency. If ${ }^{23} \mathrm{j} u$ is present in the sample, the $235: i^{237} \mathrm{Pu}$ isotopir ratio is cietermined in the same way, using the ${ }^{235} \mathrm{U}$ $135.72-k e V$ gamma-ray peak. The presence of ${ }^{235} \mathrm{U}$ is established by determining whether there is any statistically significant data in the $185.72-k e V$ region.

Several fits of the relative efficiency data to Eq. $\epsilon$ are required to determine the a coelfficients because the 164.58 - and 20,8-keV peak gamma-:ay areas must be corrected for contributio..s by $241 \mathrm{Am}$. These corrections cannot be made in a rigorous manner since they require previous knowledge of

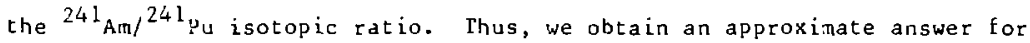
this ratio after the first fit, make corrections to the peak areas, and repeat the Eit. This iterative procedure continues until there is no statistically significant change in the results of the fit. It works because the corrections are generally never nore than $7 \%$, even for a 16 -year-old sample abundant in $241 \mathrm{Am}$.

The errors for the isotopic ratios are determined from the errors for the aj coefficients and from the goodness of fit. The error values assigned to the coefficients are determined from the inverted matrix of the weighted aquations used in the least-squares analysis. The equations are weighted 
according to the statistical errors on the peaks used to determine the relative efficiency. In this particular case, we found that the off-diagonal matrix elements of the inverted matrix were not insignificant and had to be included in the error determination.

The calculated isotopic ratios and total errors (statistical plus efficiency plus fitting) are printed out by the thermal printer. Th. printout also includes the age of the sample since separation Erom $24 \mathrm{l} A m$. This a:.e is calculated on the basis of the ${ }^{241} \mathrm{Am} /{ }^{24} \mathrm{~L}_{\mathrm{U}}$ isotopic ratio, using the standard parent-daughter reiationship. A reproduction of a typica? printout is siiswn in Fig. 3.

\section{DHERATION INSTRUCTIONS}

In this section we provide brief, step-by-step instructions for using the तata-reduction microprocessor unit to produce isotupic ratio resuits from specral data. (A more comprehensive set of instructions is provided in the unit's operations manual.) We assume that the user is familiar with the Silena $\mathrm{MCA}$ and that the Silena MCA is operationally functional, adjusted for the detector being used, and has the correct gain calibration. The accuracy of the final isotopic abundance ratios is ditectly dependent or the quality of the data. Good results cannot be obtained from poor spectral data.

OPERATING STEPS

\section{First step}

Check the voltage selection card and fuse in the power resentacle. The number on the left-liand side of the voltage selection card should watch the available AC voltage. If it does not match, change the voltage selection and the fise. Pull the stiall lever marked FUSE PULL outward to force the fuse out of its holder. Remove the voltage selection card and orient the pi board so that it shows the desired voltage on the top left side of the card. Re-insert the card. The contact strips on the card energize the proper terminals on the power supply. Return the fuse lever to normal position and install the correct fust. Slide the transparent cover hack over the voltage selection 


\section{TYPICAL DATA ANALYSIS PRINTOUT RESULTS COVERING THE 120- TO 220-keV REGION}

\begin{tabular}{|c|c|c|c|}
\hline $\begin{array}{r}7: 59 \\
\text { SPEC }=\end{array}$ & $\begin{array}{l}15 / 1 / 81 \\
14 ; L T=\end{array}$ & $1000 \mathrm{~s}$ & \\
\hline GAIN = & .1064 & $\mathrm{seV} / \mathrm{CH}$ & $\begin{array}{r}152 \cdot \text {-keV peak area } \\
7583 \pm 4.4 \%\end{array}$ \\
\hline CHNL & ZERD E & 109.457 & $\begin{aligned} 186-k e V \text { peak area } & = \\
0 & \pm 0.0 \%\end{aligned}$ \\
\hline FWHM & $1208 \mathrm{keV}$ & $=0.856$ & \\
\hline $\begin{array}{l}\text { Peak En. } \\
122.93\end{array}$ & $\begin{array}{c}\text { Counts } \\
1589\end{array}$ & $\begin{array}{r}\% \text { EF } \\
6.4\end{array}$ & $\begin{aligned} 238 \mathrm{PU} / 239 \mathrm{PU} & =0.002129 \\
& \pm 0.000098\end{aligned}$ \\
\hline 123.62 & 270 & Fixd & $240 \mathrm{PU} / 239 \mathrm{PU}=0.189621$ \\
\hline 124.51 & 854 & Fixd & $=0.006330$ \\
\hline 125.21 & 794 & Fixd & \\
\hline $\begin{array}{l}125.26 \\
129.29\end{array}$ & $\begin{array}{r}6301 \\
86634\end{array}$ & $\begin{array}{l}2.0 \\
0.4\end{array}$ & $\begin{aligned} 241 \mathrm{PU} / 239 \mathrm{PU} & =0.024358 \\
& \pm 0.000300\end{aligned}$ \\
\hline Peak En. & Counts & $\% E R$ & $241 \mathrm{AM} / 241 \mathrm{PU}=0.083424$ \\
\hline 141.57 & 545 & 15.4 & \pm 0.002162 \\
\hline 144.21 & 4434 & 2.2 & \\
\hline 146.08 & 1868 & Fixd & $235 \mathrm{U} / 239 \mathrm{PU}=0.000000$ \\
\hline 146.56 & 1237 & 7.8 & \pm 0.000000 \\
\hline 148.56 & 106729 & 0.3 & \\
\hline 150.11 & 200 & Fixd & $\begin{array}{l}\text { Time since Sep. }= \\
606.41 \pm 15.12 \text { days }\end{array}$ \\
\hline Peak En. & Counts & "\%ER & \\
\hline $\begin{array}{l}159.96 \\
160.19\end{array}$ & $\begin{array}{r}3591 \\
79\end{array}$ & $\begin{array}{l}\text { Fixd } \\
\text { Fixd }\end{array}$ & \\
\hline $\begin{array}{l}160.79 \\
160.28\end{array}$ & 3822 & 3.0 & \\
\hline 161.45 & 1524 & 5.5 & \\
\hline 164.58 & 25468 & 0. : & \\
\hline 165.93 & 127 & 59.2 & \\
\hline Peak En. & Counts & \%ER & \\
\hline $\begin{array}{l}203.54 \\
208.00\end{array}$ & $\begin{array}{r}6180 \\
234120\end{array}$ & $\begin{array}{l}1.6 \\
0.2\end{array}$ & \\
\hline
\end{tabular}

FIG. 3. Reproduction of a printout produced by the 20 -column thermal printer. 
card and the fuse. Plug the line cord into the power receptacle and then plug the line cord into the AC power source. DO NOT TURN ON POWER YET.

\section{Second Step}

The printer also has a voltage selection switch that must be set correctly before tne power can be turned on. To set this switch, withdraw the Eront panel assembly of the printer just as it is withdrawn when the paper ro:l is changed (see operations manual). Inside the printer housing, on the second printed circuit card from the left-hand side, is a blue switch mechanism labeled $110 \mathrm{~V} 2$ 20V. Set the switch to the available voltage. No Euse changes are required.

While the front panel assembly of the printer is out, check the quantity of paper on the paper roll. Approximately $30 \mathrm{~cm}$ of paper are used for a data analysis printout. The operations manual provides detailed instructions for changing the paper roll.

\section{Third step}

Connect the flat ribbon cable to the data-reduction unit and to the Silena MCA. Do this without power applied to either unit to prevent accidental damage to components on either interface boarc. since the conneccors are keyed, there is no confusion about how the connection is made.

\section{Fourth Step}

Switch the power ON to both units, but to the data-reduction unit first: the Silena MCA will $\mathrm{N}_{2}$ function properly when connected to the data-reduction unit unless the power to the data-reduction unit is on. The Silena MCA can now be operated in the normal manner by using the pushbuttons on its front panel or the identically labeled function keys on the data-reduction keyboard. The function keys are activated by pressing a key to activate the function keyboard $l i g h t$ and then pressing the ENTEk key. 
When the Eunction keys are controlling the MCA, the pushbuttons become inoperative, but they can be reactivated by pressing the kESTART switch on the keyboard. The RESIART switch releases the microprocessor unit's control of the MCA and causes the time and date to be displayed. If an error is made in the sequexce of colimands to the MCA, the message COMMAND ERROR is flashed on the display. An example of such an error would be issuing the DATA IN command while the MCA is in DISPLAY. The MCA must be in STOP before the DATA IN command can be issued.

\section{Fiftustitep}

When the power is turned on to the micropeocessor unit or the RESTART switch is pressed, tre time and date are displayed. To correct the time or the date, press the INIT key and the ENTER key consecutively. This activates the software, whicis prompts the user for the correct time and date and sets the internal clock board. The operations manual provides more detailed instructions for entering the time and the date.

\section{sixth step}

hata must be in the analyzer memory before the analys is of a spectrum can begin. Before transferring the data in the Silena MCA nemory to the data-reduction unit, make sure that the analyzer is in the display mode. Then press the START key and the ENTER key. When this command is given, the analyzer will go to the DATA OUT mode and back to DISPLAY in less than a second. When the analyzer is in the DATA OUT mode, data are being tranferred from the silena MCA memory to the data-reduction unit memory. When the transfer is complete, the tine and date shown on the display are princed. The spectruin number and livetime are also printed automatically if they are passed from the analyzer during the data transfer. If this information is not transferred--which is posuible since not all Silena MCA models have PROM IC's programmed to transfer spectrum number and livetime--the user is prompted and he enters it on the data-reduction keyboard. (Instructions for this type of entry are given in the operations manual.) 
Seventh Step

Once the data transfer is complete, the message "148 PEAK pos" will appear on the alphanumeric display. Determine the nearest channel address corresponding to the peak channel position of the ${ }^{24 \mathrm{l}} \mathrm{Pu}$ 148.6-keV gamma-ray peak and enter the ciunnel number value on the numeric keyboard. If the value shown on the keyboard display is incorrect, press the CLEAR key and enter the correct value. The entered valus will appear on the alphanumeric display for approximately $5 \mathrm{~s}$, and then the message "208 PEAK POS" will appear. Enter the nearest channel address of the ${ }^{237} \mathrm{U} 208-\mathrm{keV}$ gamma-ray peak. The entered value will appear on the alphanumeric display. The software checks the entered peak positions for validity. If all requirements are met, the program continues with the analysis of the spectral data, and the results are printed out. The end of the analysis is indicated by a display of the current time and date.

\section{Eighth $\underline{\text { Step }}$}

You may turn oif power to both units in either order--data reduction unit Eirst and MCA second or MCA first and data-reduction unit second. However, if you are only curning off power to the data-reduction unit, you must disconnect it from the MCA if the MCA is to operate normally. We recommend that power to the data-reduction unit not he switched off intermittently. Such action may result in damage to the switching power supply.

\section{ERRUR DIAGNOSTICS}

We have incorporated several checks into the software to detect situations that might cause errors or porr results. If certain conditions are not met by the spectral data or the information entered by the user, the following error messages are flashed on the alphanumeric display.

BAD PEAK POSITION. If statistically significant data do not exist near the peak positions indicated by the user in response to the peak-position 
queries, the error message BAD PEAK POSITION is flashed on the display. This indicates that either an incorcect value was entered for a peak position or no data were transferred from the analyzer to the microprocessor. Instead of cuntiuning, the program returns to the beginning and waits for the user to take corrective action and restart the analysis.

BAD ZERU; CHECK PUS. If statistically siguificant peaks are found, the software proceeds w determine more accurate peak positions from which the gain and ciannel-zero enerzy of the spectrum are calculated. The results, along with the FWhy, are printed out, and the gain and zero are checked to ensure that the spectral information required fur the isotopic analysis--i.e., the first Eour peak groupings--i- included in the spectrum. If the chamel-zero energy is greater than $121.5 \mathrm{keV}$, the message Bhif ZiRO; LHELK pOS is flashed on the display. This indicates that channel-zero energy precludes analysis of the 120 -kev peak yrouping, which is required by the software. This condition may exist because of an incorrect peak posicion encry ar an improper energy calibration of the amplifier/and yzer.

BAib GiN; CHECK POS. If the product of the spectrum aain and maximum channel in the spectrum (1000 or 2000 , depending on the andlyzer) is less than $210 \mathrm{keV}$, the message BAD LALN; CHECK PUS is displayed. The microprocessor software cannot analyze the spectrum if the 208-keV peak region 15 not included. So, again, either the correct peak position must be entered or the spectrum retaken with the proper energy calitration of the amplifier/analyzer.

CHECK PEAKS. Another error mav occur in determining the FWHM parameter as a function of energy, expressed by Eq. 3. It the peak shape analysis results in a value of $K_{1}$ less than 0 , the message CHECK PEAKS is flashed on the display. This error occurs jf the 148.6- and 208-keV calibration peaks have very poor counting statistics, if the incorrect peak positions have been entered, or if either peak has a channel that has overflowed. Channel overflow is most likely in the 208-keV peak and results in a 
distorted peak shape. When a channel overflows, a spectrum cannot be analyzed. Since we presently have no correction for overflow, the user must guard against it.

POOR RESOLUTION. If the FWHM of the 208-keV peak exceeds $1.15 \mathrm{keV}$, the message POOR RESOLUTION is flashed on the display. This warns the user that the spectral resolution is not good and that the results are questionable. Although the data will be analyzed, the user should take action to improve the energy resolution. Such action might involve reducing th. detector count rate or adjusting the amplifier pole and shaping the time constant (see the silena operations manual :or more details). An energy resolution of 1.15 tiev at the $208-\mathrm{keV}$ peak is a reasonable value for a large coaxial germanium detector; however, for a smalier planar detector, an energ; resolution of $0.8 \mathrm{keV}$ can be attained. Since the software is written for all types of germanium detectors, we use an upper limit energy resolution of $1.15 \mathrm{keV}$ at the 209-keV peak for all spectra.

DATA ANALYSIS RESULTS

We assessed the perfornance of the data reduction unit witn spectra of NBS plutonium isotopic reference materials--NBS-SRM 94h, 947, altd 948--and with spectra taken by the IAEA. Both sets ot data were taken with a Silena MCA and a $13-\mathrm{cm}$ planir HPGe detector.

Our measurement:s included four spectra of each NBS standard: two taken with a conversion gain of $0.11 \mathrm{keV} / \mathrm{channel}$, for livetimes of 2,000 and $20,000 \mathrm{~s}$, and two raken with the same set of livetimes and a conversion gain of $0.34 \mathrm{keV} / \mathrm{channel}$. The intent of these measurements was to obtair a better insight into the variation of results caused by the peak area analysis algorithm and the correction for detection efficiency. All spectra were collected with analyzer deadtimes of less than $20 \%$ to rejuce the effects of a high count rate. Figure 4 shaws a 20,000-s spectrum of NBS sample 947 raken with our Silena system. 


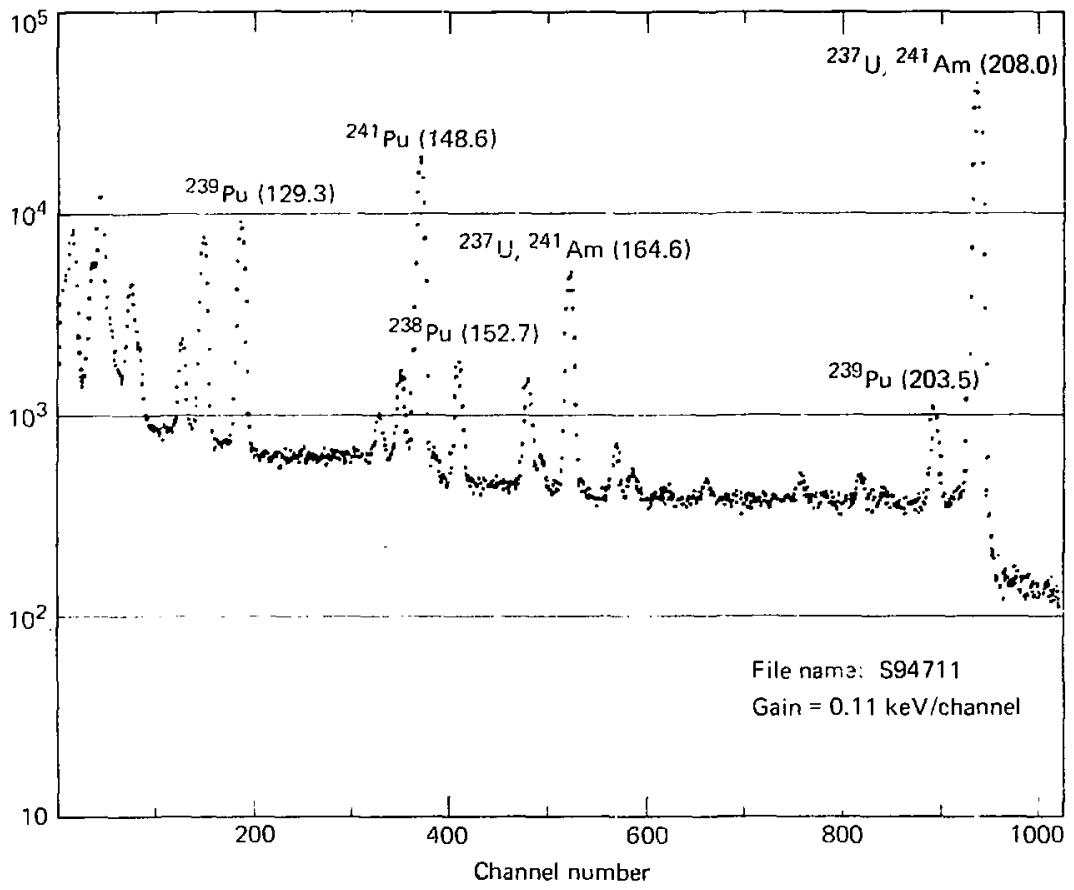

FIC. 4. The 110- to 21 ?-keV gamma-ray spectral region of NBS 947 taken with a Silena $B S 27 / N$ analyzer.

The results obtained for NBS standards 946,947 , and 948 , for each of the three isocopic ratios-- ${ }^{238} \mathrm{Pu} /{ }^{239} \mathrm{Pu},{ }^{240} \mathrm{Pu} /{ }^{239} \mathrm{Pu}$, and ${ }^{241} \mathrm{Pu} /{ }^{239} \mathrm{Pu}--$ are plotted in Figs. 5, 6, and 7. The ordinate values for each plot are the isotopic ratios obtained by the data-reduction unit (designated by IAEAPU) divided by the isotopic ratio calculated from the updated NBS reference values. The half-lives used in the gamma-ray spectrum analyses were used to update the NBS isotopic abundances. At the time of measurement chese were: 
NBS 946 $\quad \underline{\text { NBS } 947 \quad \text { NBS } 948}$

$\begin{array}{lrrr}\% 238 \mathrm{Pu} & 0.23 & 0.28 & 0.01 \\ \% 239 \mathrm{Pu} & 84.32 & 76.94 & 91.72 \\ \% 240 \mathrm{Pu} & 12.23 & 18.58 & 7.62 \\ \% 241 \mathrm{Pu} & 2.6^{4} & 3.00 & 0.32 \\ \% 242 \mathrm{Pu} & 0.58 & 1.20 & 0.03\end{array}$

The Eirst two data points for each sample are from the spectra with the lower conversion gain. The tirst data point of each pair is fron the spectrum with the shorter liverime accum, lation.

The scatter of the data for the ${ }^{238} \mathrm{Pu} /{ }^{239} \mathrm{Pu}$ isotopic ratio results is relatively small from samples NBS ?'6 and NBS 947, with standard deviations ranging between 1.9 and $2.3 \%$. The larger variation in the results, obtained

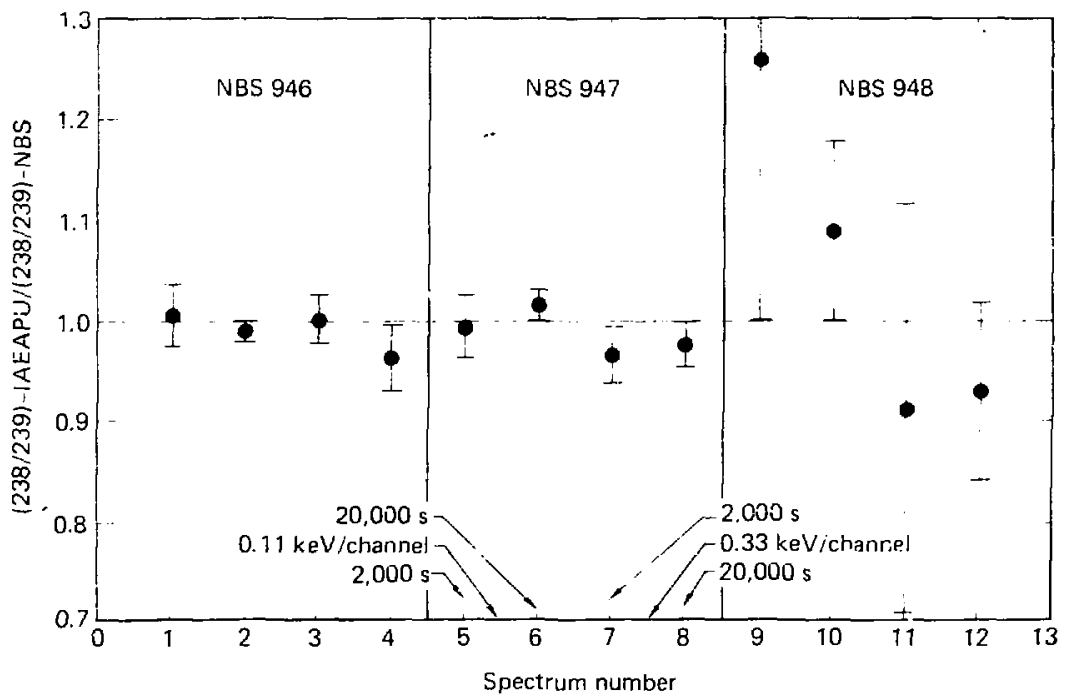

EIG. 5. $238 \mathrm{pu} / 239 \mathrm{pu}$ isotopic ratio rosults obtained with the data-reduction unit (IAEAPU) divided by NBS valies. 


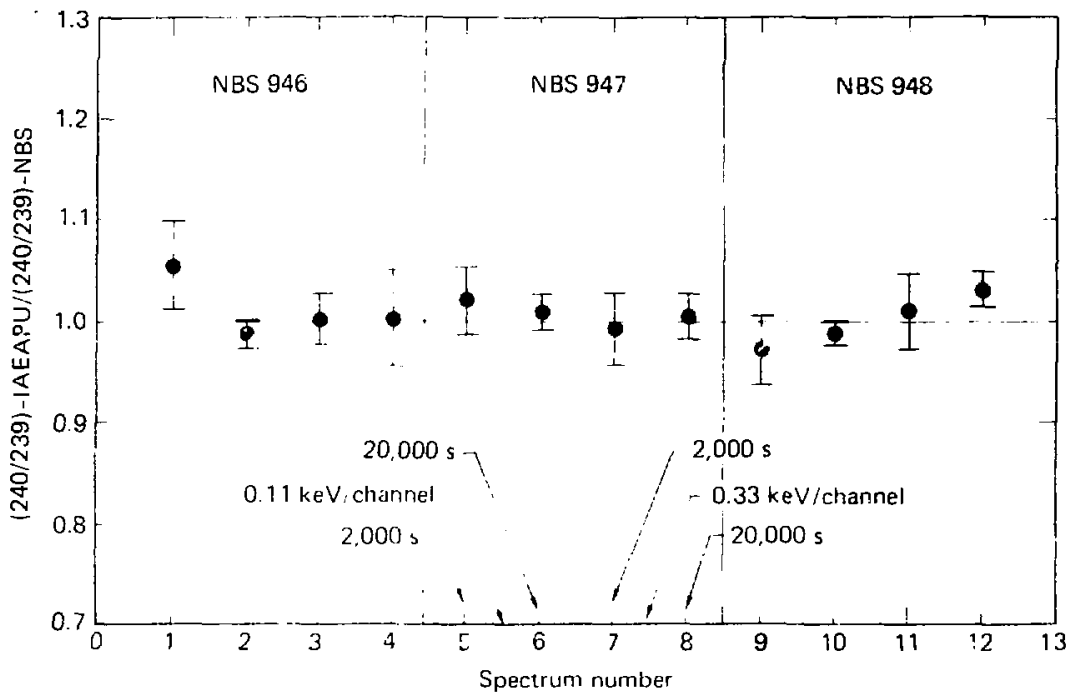

Fi:3. 6. 24jpu/23t!y isotopir rativ results ontained with the data-redisticn whit (IAEAPl) rivided by ils values.

for sample NBS 948 , is mainly due to the poor counting statistics of the 152-keV gamma-ray peak ot ${ }^{238} \mathrm{Pu}$, an isotope that has a very tow abundance in NBS 948. (Our initial results for the ${ }^{238} \mathrm{Pu} /{ }^{239} \mathrm{Pu}$ ratio showed a bias of approximately $2.0 \%$. The results shown here reflect a reduction in the 238 Fu $152-\mathrm{keV}$ gamma-ray branching racio of $9.0 \%$, from $9.56 \times 10^{-6}$ to $9.32 *$ $10^{-6}$. This discrepancy is also mantioned in the ESARDA study ${ }^{3}$ and the Mound Laboratury work. ${ }^{4}$ )

The ${ }^{240} \mathrm{Pu} /{ }^{239} \mathrm{Pu}$ ratio is obtained by analyzing the complex mulciplec at $160-\mathrm{keV}$. This umltiplet consists of a peak at $159.96 \mathrm{keV}$ from $24 \mathrm{l}_{\mathrm{Pu}}$ a peak at $160.19 \mathrm{keV}$ from ${ }^{239} \mathrm{Pu}$, and the ${ }^{240} \mathrm{Pu}$ peak at $160.28 \mathrm{keV}$. Since the energy separation of the ${ }^{2{ }_{1} \mathrm{~L}} \mathrm{Pu}$ peak and the ${ }^{240} \mathrm{Pu}$ peak is less tinan the energy resolution of the detector at this energy, fitting eacl. peak separately, with many free parameters, can produce poor results. The method of generating isotopic component respunse functions dercibed earlier reduces the number of free parameters to the number of isotopis components. The 


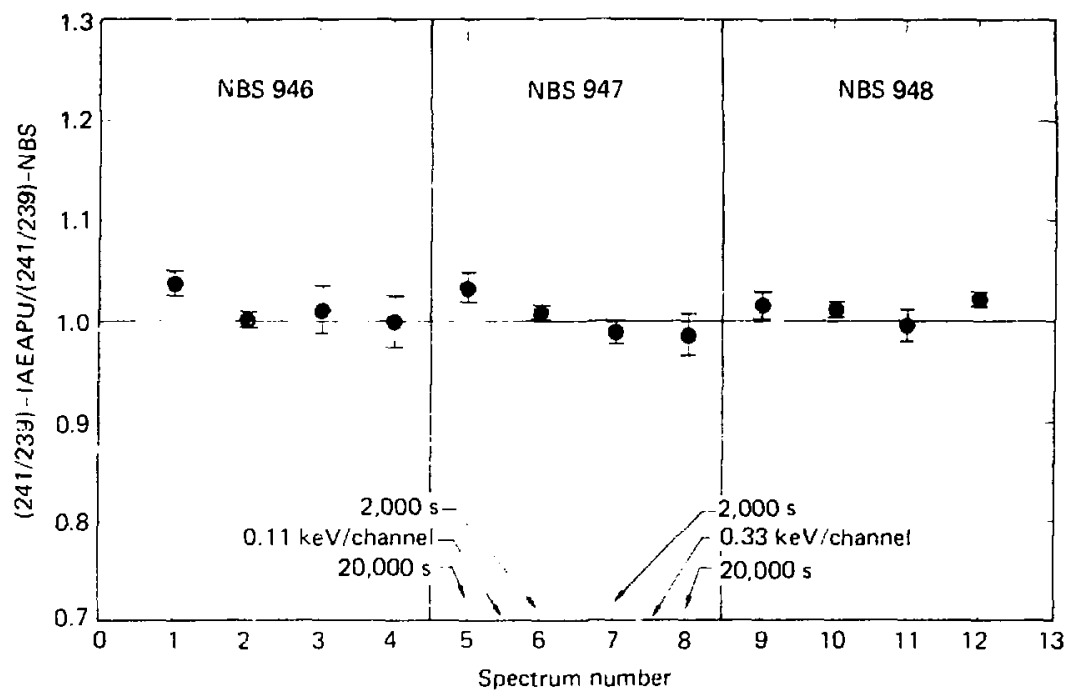

FIG. 7. $241 \mathrm{pu} / 239_{\text {Pu }}$ isstopic ratio results obtained with the data-reduction unit (intipu) divided by NBS values.

incensity and position of the $159.95-k e V$ peak is fixed to the 164.58-keV peak and the two 239 pu peaks are fixed to each other. In the case of the 1.at.joand the 154.96-keV peaks, we apply a small correction in the 164.5s-keV peak intensity for the ${ }^{24} \mathrm{Am}$ concribution. For older NBS s-aniards, thia cortection is slightly less than $7 \%$. The standard deviations of the results ranged from 1.4 to $3.0 \%$.

The results oncained for the $24 \mathrm{pu}^{23} \mathrm{p}^{3}$ isotopic ratio are in excellent agreanent with the NBS reference vai.es. This rath is detaraiacd primarily by the ${ }^{239} \mathrm{Pu} 2133.5-\mathrm{keV}$ and $237 \mathrm{U} 2198-\mathrm{keV}$ peak pair. The observed scatter in the results ar: ses mustly from variations in the determination of the $303.5-k e V$ peak area and from the correction of the 20b-keV prak for tne contribut ton from 241 in. Errors fran efficiency correction are small compared with those from determining peak areds for this pair of gamma rays.

The generally good agreement obtained with iss reference values lends confidence to the spectral datz analysis method used by the data-reduction unit. There does not appear to be any systematic error in tne method for 
determinug paik alezs since both positive and nezative biases are observed for different isotopic ratins. The results suggest that small corrections, on the order of 2-36, are riquired in published values for the branching

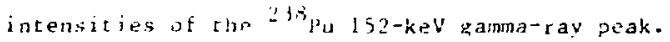

Thr IAtid proviled is with lis gama-rav spect:a, "expected" Isotopic

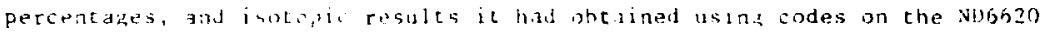
system (see ippentilx). The 14 spectra were taken with data accumulation livet thes rangin: fron l, vilu to $4,000 \mathrm{~s}$. The conversion gains for tnese

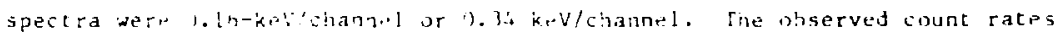

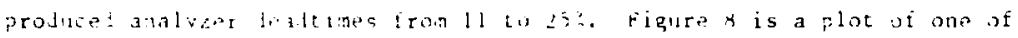

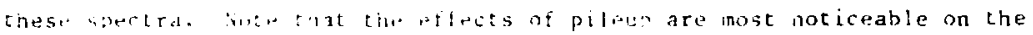

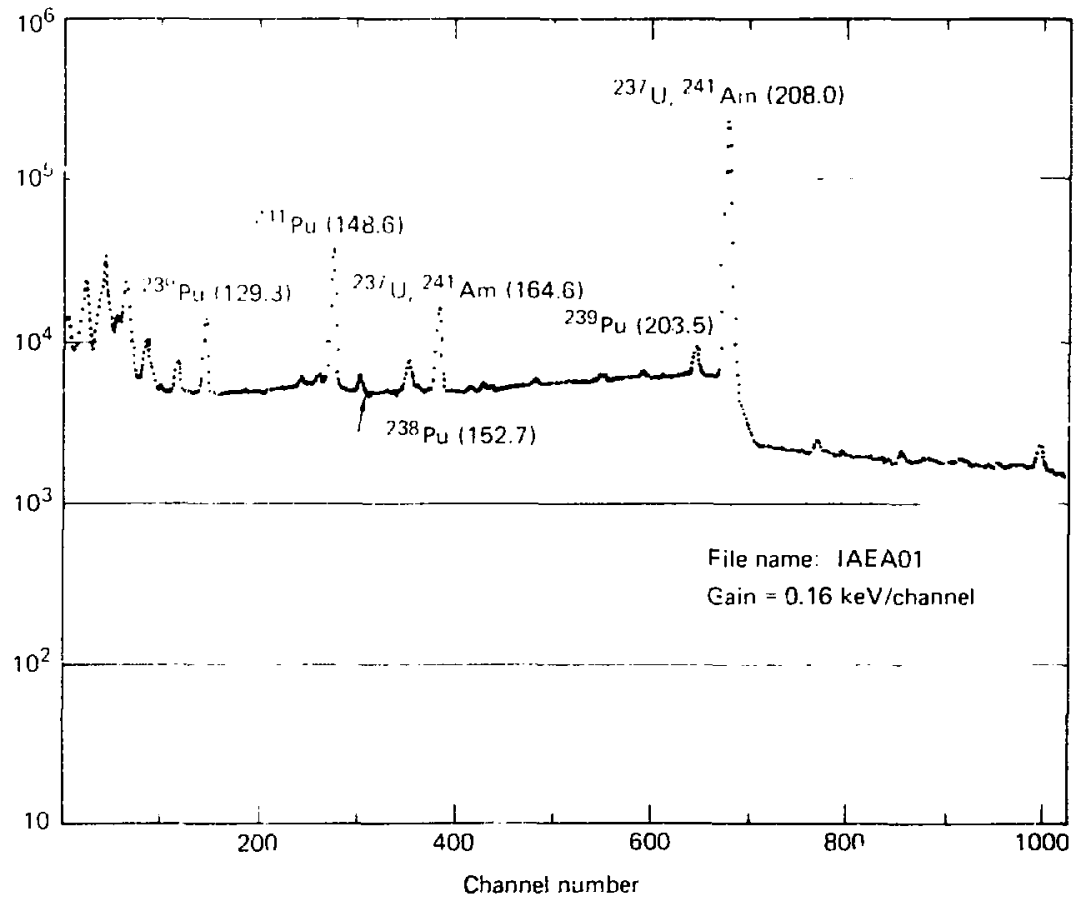

FIG. b. The lob-to $260-k e V$ gamma-ray spectral region of a pluconium sanple taken by the IAEA. 
high-energy side of the 208-keV peak. A considerable amount of forward scatter: $;$, indicated by the long up-sloping plateaus below each peak grouping, is also evident in these spectra. Both these effects increase the uncertainty in the determination of the background.

The results obtained for the ${ }^{238} \mathrm{Pu} /{ }^{239} \mathrm{Pu},{ }^{240} \mathrm{Pu} /{ }^{239} \mathrm{Pu}$, and ${ }^{24} \mathrm{Pu} /{ }^{239} \mathrm{Pu}$ isotopic ratios using the data-reduction unit and codes on the ND6620 system are plotted in Figs. 9, 10, and 11. The ordinate values for each plot are the isotopic ratios obtained from the data-reduction unit divided by the "expected" isotopic ratio results. The IALA's "expected" isotopic abundances were:

Group l Group II Group III

$\begin{array}{lccc}\% 238 \mathrm{Pu} & 0.140 & 10.1335 & 1.378 \\ \% 239 \mathrm{Pu} & 75.34 & 75.24 & 57.58 \\ \% 240 \mathrm{Pu} & 20.947 & 20.93 & 24.44 \\ \% 241 \mathrm{Pu} & 2.9156 & 3.206 & 11.29\end{array}$

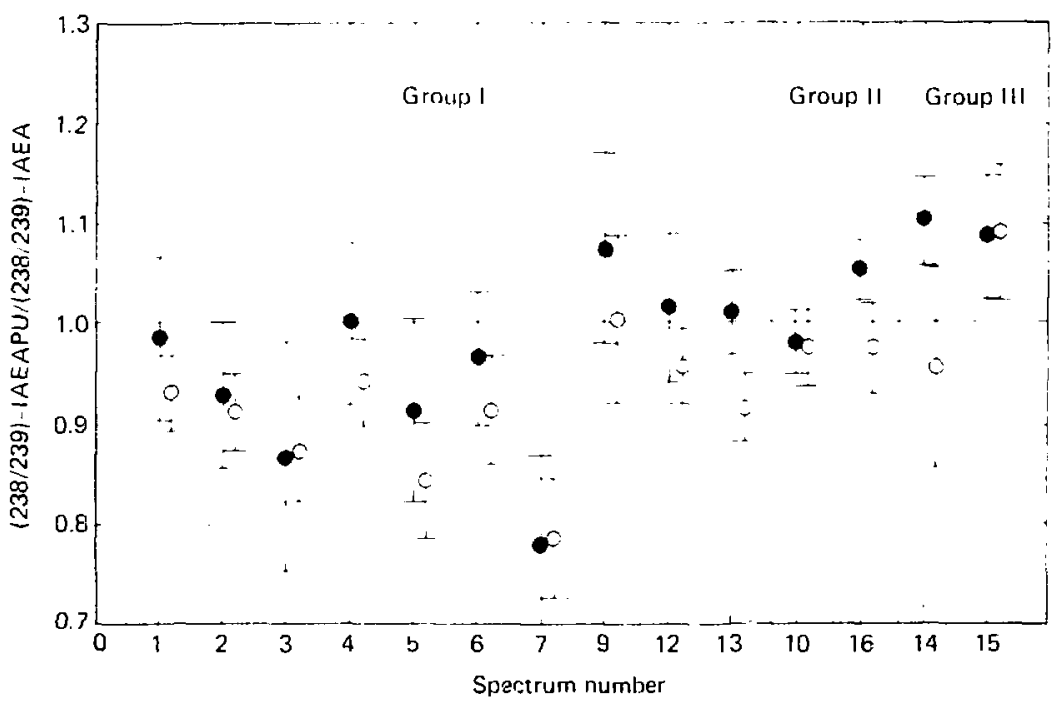

FIG. 9. $238_{\mathrm{pu} / 239} \mathrm{Pu}$ isotopic ratio results obcained with the data-reduction unit (IAiAPU) ( $)$ and with ND6620 codes (o) divided by IAEA "expected" results. 


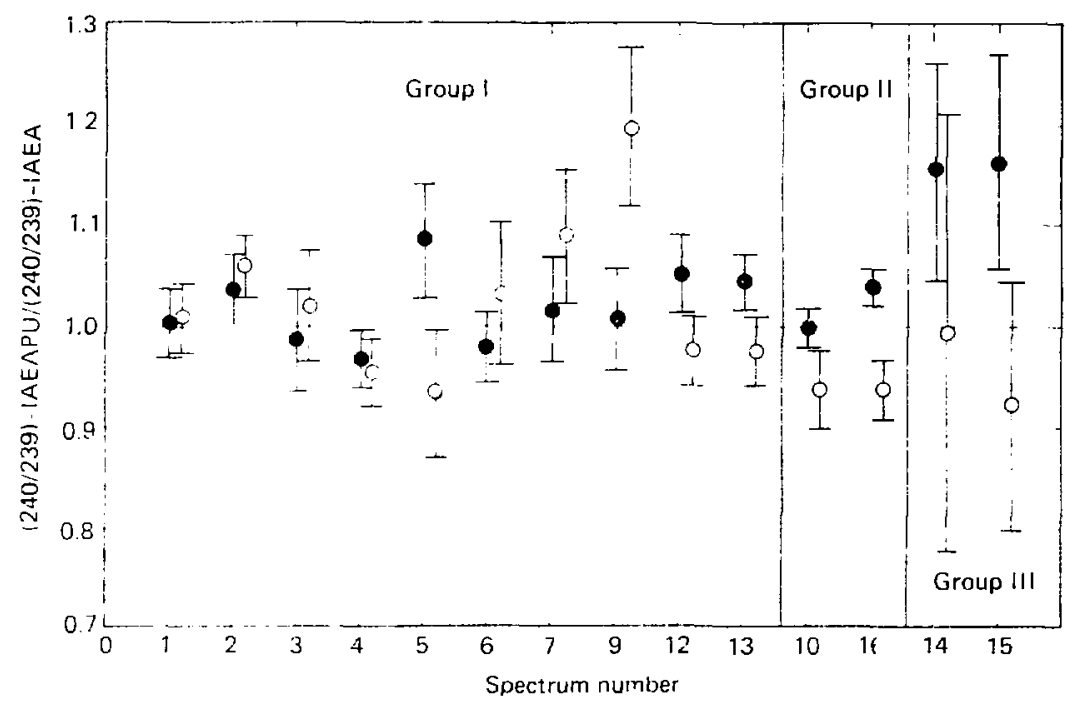

FIG. 10. 2419u/2ija isotoplc ratio results obtained with the data-reduction unit (IAtAPU) (a) and with ind5620 codes (o) dividert bu the IAtA "expected" results.

There is considerable scatter in the data-reduction untt results as well as in the NDbo2u results. In general, our results are in agreement with the Nu6620 results, which leads one to believe that the observed differences are due to the quality of the acquired data or to incorrect "expected" isotopic percentages but not to the method of spectral analysis. The only really significant bias between our results and the No662u results is che ${ }^{240} \mathrm{Pu} /{ }^{239} \mathrm{Pu}$ isotopic ratio for spectra 14 and 15 . These spectra are of sample III--the higher burnup material. It is not clear what causes the difference. Since both of these spectra were caken at rather high count rates (25\% deadtime), one possibility might be the pileup of $159.96-k e V$ erints into the $160.28-k e V$ region.

Comparison of the results obtained from spectra taken with a conversion gain of $0.34 \mathrm{keV} / \mathrm{channel}$ and spectra taken with a conversion gain of 0.16 $\mathrm{keV} / \mathrm{channel}$ indicates that little or no inforination $\mathrm{i}$. ained by including the $330-\mathrm{keV}$ and $370-\mathrm{keV}$ regions. In most cases the errors ar ising from the 
results are greater because poorer counting statistics in the 300-keV region make the determination of the relative efficiency curve less reliable.

If the $300-k e V$ region is chosen, then more attention should be given to the detector-absorber arrangement to improve the counting statistics at these energies. But even if this is done, longer counting times will be requ red. With the iterative method, used in the data-reduction unit for determining the relative efficiency curve, convergence is less likely if the ${ }^{241}$ Pu gamma rays in the $300-k e V$ region are included because significant ${ }^{241} \mathrm{Am}$ contribution must be subtracted from the ${ }^{241} \mathrm{Pu}$ peaks. We recommend that gamma-ray spectra extending through the 300-keV region not be taken.

If these 14 spectra are typical of the in-the-field spectra taken by IAEA inspectors, then our results indicate that the portable microprocessor unit will perform as well in the field as the ND6620 system does at its home base. of course, the unit still requires extensive laboratory testing, and perhaps Field trials, before we can make a complete evaluation of its performance. The unit was developed not only to reduce data in the field but also to aid

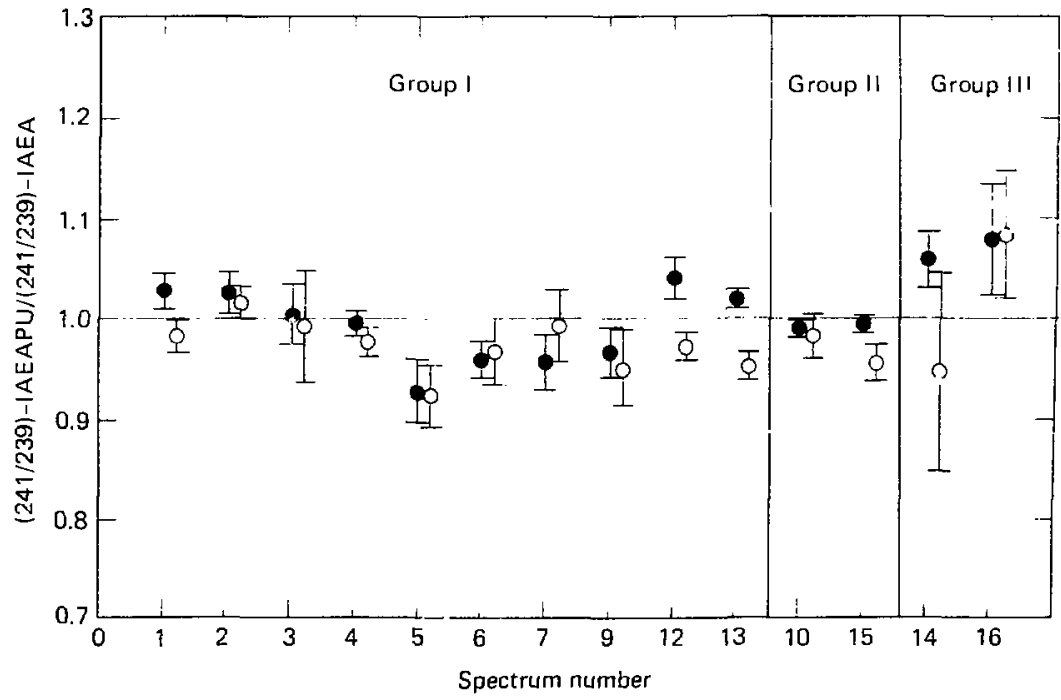

F[G. $11.241_{\mathrm{Pu}} / 23 \% \mathrm{Pu}$ isotopic ratio results obtained with the data-reduction unit (IAEAPU) (๑) and with ND6620 codes (o) divided by IAEA "expected" results. 
the user in taking better quality spectra. It was built to be flexible for future use: we could easily upgrade its hardware and software for additional calculations and use it as the central processing unit of a lightweight minicomputer system.

\section{ACKNOWLEDGMENTS}

We acknuwledge the contributions of $\%$. DeCarolis, D. Rundquist, $G$. Nelson, $A$. Ranalho, and others, of the ldfi, for their assistance in this rask. We tiank J. Skalyo, Jr., of LSpo, brookhaven, for his advice and guidance during the course of this task. We thank $K$. Dewitc, $R$. Gunnink, and $\therefore$ Prindle, of Lawrence Livernore National Laboratory, for their assistance and advice in this wirk.

\section{REFERENCF:S}

1. R. Gunnink, J. B. Nitay, and P. D. Siemens, A system for Plutonium Analysis by ijina-kay Spectrometry, Part l: Techniques for Analysis of

Sulucion, Lawrence Livermore National Laboratory, Livermore, Cd, JCKL-51577 (1974).

2. R. Gurniuk, J, L. Evans, and A. L. Prindle, A Re-evaluation of the Gam :-Ray Energies and Absolute Branching lntensities of 237 U, $238-241$ Pu, a i Am, Lawrence Livermore National Laboratory, Livermore, CA, LCRL-52139 (1975).

3. H. Uttmar, "Results from an Interlaboratory Exertise on the Betermination of Plutonium Composition by Gamma Spectrometry," in Proc. Instifute of Nuclear Materials Management Meeting, July 1979, Vol. VIl I.

4. J. Fleissner, J. Lemning, and J. Jarvis, "Study of a Two-Detector Method Eor Measuring Plutonium Isotopies," in Proc. Ain. Nuc. Soc. Topical Meeting, Kiawah Island, South Carolina, 1979 (National Bureau of Standards, 1979), p. 555. 


\section{APPENDIX}

This appendix contains the isotopic results provided by the IAEA. They are listed with the errors obtained using the ND6620 system and its spectral analysis software. The data are in the form of isotopic ratios (open circles) in Figs. 9, 10, and 11 . The results given in parentheses are the "expected" results, Each numbered spectrum was sent to LLNL and analyzed by the laEAPU code. The filled-in circles in Figs. 9, 10, and 11 indicate the ${ }^{238} \mathrm{Pu} /{ }^{239} \mathrm{Pu},{ }^{240} \mathrm{Pu} /{ }^{239} \mathrm{Pu}$, and ${ }^{241} \mathrm{Pu} /{ }^{239} \mathrm{Pu}$ isotopic ratios. 
TABLE A1. Isotopic composition of samples.

\begin{tabular}{|c|c|c|c|c|c|c|c|c|c|}
\hline $\begin{array}{l}\text { Spectrum } \\
\text { number }\end{array}$ & $\begin{array}{l}\text { Sample } \\
\text { number }\end{array}$ & $\begin{array}{c}\text { keV/ } \\
\text { channel }\end{array}$ & $\begin{array}{l}\text { Dead- } \\
\text { time }\end{array}$ & $\mu_{\pi}^{238} \mathrm{Pu}$ & $z^{239} \mathrm{Pu}$ & $:^{240} \mathrm{Pu}$ & $\% 2+1 \mathrm{Pu}$ & $241_{\mathrm{Am} /}^{\text {Racio }} / 24 \mathrm{Pu}$ & $\begin{array}{l}\text { Age } \\
(y)\end{array}$ \\
\hline 1 & & .148 & $16 \%$ & $\begin{array}{c}.130 \pm .005 \\
(.140)\end{array}$ & $\begin{array}{l}75.2 \pm 0.7 \\
(75.34)\end{array}$ & $\begin{array}{l}21.1 \pm 0.7 \\
(20.947)\end{array}$ & $\begin{array}{l}2.85 \pm 0.04 \\
(2.908)\end{array}$ & $0.240 \pm 0.006$ & $4.5 \pm 0.1$ \\
\hline 2 & & .148 & $17 \%$ & $\begin{array}{c}.126 \pm 1) .005 \\
(.140)\end{array}$ & $\begin{array}{l}74.4 \pm 0.6 \\
(75.34)\end{array}$ & $\begin{array}{l}21.9 \pm 0.5 \\
(24.947)\end{array}$ & $\begin{array}{l}2.92 \pm 0.04 \\
(2.908)\end{array}$ & $0.230 \pm 10.007$ & $4.3+0.1$ \\
\hline 3 & & .148 & $20 \%$ & $.122 \pm .007$ & $\begin{array}{l}75.1 \pm 1.1 \\
(75.34)\end{array}$ & $\begin{array}{l}21.3 \pm 1.1 \\
(20.947)\end{array}$ & $\begin{array}{l}2.88 \pm 0.06 \\
(2.908)\end{array}$ & $0.224 \pm 0.014$ & $4.2 \pm 0.2$ \\
\hline 4 & & .161 & $11 \%$ & $\begin{array}{c}.133 \pm .006 \\
(.140)\end{array}$ & $\begin{array}{l}76.1 \pm 0.7 \\
(75.34)\end{array}$ & $\begin{array}{l}20.2 \pm 0.7 \\
(20.947)\end{array}$ & $\begin{array}{l}2.87 \pm 0.03 \\
(2.903)\end{array}$ & $0.250 \pm 0.006$ & $4.6 \pm 0.1$ \\
\hline 5 & & .337 & $19 \%$ & $\begin{array}{c}.120 \pm .008 \\
(.140)\end{array}$ & $\begin{array}{c}76.5 \pm 1.3 \\
(75.94)\end{array}$ & $\begin{array}{l}19.9 \pm 1.3 \\
(20.947)\end{array}$ & $\begin{array}{l}2.73 \pm 0.08 \\
(2.908)\end{array}$ & $0.264 \pm 0.013$ & $4.9 \pm 0.2$ \\
\hline 6 & & .337 & $20 \%$ & $\begin{array}{c}.127 \pm .007 \\
(.140)\end{array}$ & $\begin{array}{c}74.9 \pm 1.4 \\
(75.34)\end{array}$ & $\begin{array}{l}21.5 \pm 1.4 \\
(20.947)\end{array}$ & $\begin{array}{l}2.80 \pm 0.08 \\
(2.908)\end{array}$ & $0.264 \pm 0.014$ & $4.4 \pm 0.2$ \\
\hline 7 & & .337 & $20 \%$ & $\begin{array}{c}.108 \pm .008 \\
(.140)\end{array}$ & $\begin{array}{c}74.0 \pm 1.3 \\
(75.34)\end{array}$ & $\begin{array}{l}22.4 \pm 1.3 \\
(20.947)\end{array}$ & $\begin{array}{l}2.84 \pm 0.09 \\
(2.908)\end{array}$ & $0.29 \pm 0.09$ & $5.3 \pm 0.3$ \\
\hline 9 & & .337 & $20 \%$ & $\begin{array}{c}.135 \pm .011 \\
(.140)\end{array}$ & $\begin{array}{l}72.4 \pm 1.5 \\
(75.34)\end{array}$ & $\begin{array}{l}24.1 \pm 1.5 \\
(20.947)\end{array}$ & $\begin{array}{c}2.66 \pm 0.09 \\
(2.908)\end{array}$ & $0.235 \pm 0.011$ & $4.4 \pm 0.2$ \\
\hline 10 & a & .337 & $20 \%$ &.$^{.132 \pm} .005$ & $\begin{array}{l}76.3 \pm 0.8 \\
(75.24)\end{array}$ & $\begin{array}{l}19.9 \pm 0.8 \\
(20.93)\end{array}$ & $\begin{array}{l}3.00 \pm 0.06 \\
(3.006)\end{array}$ & $0.26 \pm 0.01$ & $4.8 \pm 0.2$ \\
\hline
\end{tabular}


TABLE Al. Continued.

\begin{tabular}{|c|c|c|c|c|c|c|c|c|c|}
\hline $\begin{array}{l}\text { Spectrum } \\
\text { number }\end{array}$ & $\begin{array}{l}\text { Sample } \\
\text { number }\end{array}$ & $\begin{array}{c}\text { keV/ } \\
\text { channel }\end{array}$ & $\begin{array}{l}\text { Dead- } \\
\text { time }\end{array}$ & $\%^{238} \mathrm{Pu}$ & $\%{ }^{239} \mathrm{Pu}$ & $\%{ }^{240} \mathrm{Pu}$ & $\%^{24 I} \mathrm{Pu}$ & $\begin{array}{c}\text { Ratio } \\
24 \mathrm{l}_{\mathrm{Am} /} / \mathrm{fl}_{\mathrm{Pu}}\end{array}$ & $\begin{array}{l}\text { Age } \\
(y)\end{array}$ \\
\hline 11 & b & $.16 \mathrm{l}$ & $22 \%$ & $\begin{array}{l}.129 \pm .005 \\
(.1335)^{2}\end{array}$ & $\begin{array}{l}75.9 \pm 0.7 \\
(75.24)\end{array}$ & $\begin{array}{l}20.5 \pm 0.7 \\
(20.93)\end{array}$ & $\begin{array}{l}2.83 \pm .05 \\
(3.009)\end{array}$ & $0.37 \pm .03^{c}$ & $=$ \\
\hline 12 & & .161 & $22 \%$ & $\begin{array}{c}.135 \pm .005 \\
(.140)\end{array}$ & $\begin{array}{c}75.9+0.8 \\
(75.34)\end{array}$ & $\begin{array}{l}20.6 \pm 0.7 \\
(20.947)\end{array}$ & $\begin{array}{l}2.35 \pm 0.03 \\
(2.908)\end{array}$ & $\begin{array}{c}0.252 \pm 0.004 \\
--\end{array}$ & $\begin{array}{l}4.7 \pm 0.1 \\
--\end{array}$ \\
\hline 13 & & $.16 \mathrm{l}$ & $19 \%$ & $\begin{array}{c}.129 \pm .005 \\
(.240)\end{array}$ & $\begin{array}{c}75.9 \pm 0.7 \\
(75.34)\end{array}$ & $\begin{array}{l}20.6 \pm 0.7 \\
(20.947)\end{array}$ & $\begin{array}{l}2.79 \pm 0.03 \\
(2.908)\end{array}$ & $\begin{array}{c}0.254 \\
--\end{array}$ & $\begin{array}{l}4.7 \pm 0.1 \\
--\end{array}$ \\
\hline 14 & & .161 & $25 \%$ & $\begin{array}{c}1.33 \pm .10 \\
(1.378\rangle\end{array}$ & $\begin{array}{c}58.2 \pm 4.3 \\
(57.68)\end{array}$ & $\begin{array}{l}24.5 \pm 3.1 \\
(24.44)\end{array}$ & $\begin{array}{c}10.8 \pm 0.8 \\
(11.29)\end{array}$ & $0.086 \pm 0.005$ & $2.7 \pm 0.1$ \\
\hline 15 & & .343 & $25 \%$ & $\begin{array}{l}1.51 \pm .07 \\
(1.378)\end{array}$ & $\begin{array}{l}57.9 \pm 2.4 \\
(57.68)\end{array}$ & $\begin{array}{l}22.6 \pm 2.9 \\
(24.44)\end{array}$ & $\begin{array}{l}12.3 \pm 0.5 \\
(11.29)\end{array}$ & $0.068 \pm 0.004$ & $1.4 \pm 0.1$ \\
\hline 16 & & .343 & $25 \%$ & $\begin{array}{l}.132 \pm .06 \\
(.1335)\end{array}$ & $\begin{array}{l}76.3 \pm 0.6 \\
(75.24)\end{array}$ & $\begin{array}{l}19.9 \pm 0.6 \\
(20.93)\end{array}$ & $\begin{array}{l}2.92 \pm 0.05 \\
(3.009)\end{array}$ & $0.244 \pm 0.010$ & $4.5 \pm 0.2$ \\
\hline
\end{tabular}

\footnotetext{
${ }^{a}$ Uranium-235/total Pu ratio measured to be $.024 \pm .005$ (.017), without correction for the $184.55-k e V$ and $188.23-k e V$ gamna rays of ${ }^{239} \mathrm{Pu}$, which may interfere with the 185.718 -keV gamma-ray peak of ${ }^{235} \mathrm{U}$.

buranium-235/cotal Pu rati, measured to be .031 \pm .005 (.017), without correction Eor the 184.55-keV and 188.23-keV gamma rays of ${ }^{239} \mathrm{Pu}$, which may interfere wich the 185.718 -keV gamma-ray peak of ${ }^{235} \mathrm{U}$.

This value is doubcful because the $225-k e V$ peak was not available for analysis. Thus, the 241 Am analysis is based primarily on the ${ }^{241}$ Am $146.557-k e V$ gamma ray, which appears as a single peak with the 146.077-keV gamma ray of 239 Pu.
} 